\title{
Increasing Incidence of Invasive Group A Streptococcus Disease in First Nations Population, Alberta, Canada, 2003-2017
}

Gregory J. Tyrrell, Christopher Bell, Lea Bill, Sumana Fathima

The incidence of invasive group A Streptococcus (iGAS) disease in the general population in Alberta, Canada, has been steadily increasing. To determine whether rates for specific populations such as First Nations are also increasing, we investigated iGAS cases among First Nations persons in Alberta during 2003-2017. We identified cases by isolating GAS from a sterile site and performing emm typing. We collected demographic, social, behavioral, and clinical data for patients. During the study period, 669 cases of iGAS in First Nations persons were reported. Incidence increased from 10.0 cases $/ 100,000$ persons in 2003 to 52.2 cases/100,000 persons in 2017 . The 2017 rate was 6 times higher for the First Nations population than for non-First Nations populations (8.7 cases $/ 100,000$ persons). The 5 most common emm types from First Nations patients were 59, 101, 82, 41, and 11 . These data indicate that iGAS is severely affecting the First Nations population in Alberta, Canada.

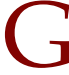
AS disease is caused by the gram-positive coccus Jbacterium Streptococcus pyogenes; invasive GAS (iGAS) disease is typically defined as identification of GAS from any sterile site, including blood, cerebrospinal fluid, brain, and deep tissues. GAS affects persons worldwide and causes a wide array of diseases including pharyngitis, skin infections (e.g., impetigo and cellulitis), bacteremia, pneumonia, septic arthritis, rheumatic fever, rheumatic heart disease, and the severe invasive diseases necrotizing fasciitis and streptococcal toxic shock syndrome $(1,2)$. The epidemiology of many of these diseases varies by
\end{abstract}

Author affiliations: University of Alberta, Edmonton, Alberta, Canada (G.J. Tyrrell); Alberta Precision Laboratories-Public Health-Alberta Health Services, Edmonton (G.J. Tyrrell); Alberta Ministry of Health, Edmonton (C. Bell, S. Fathima); Alberta First Nations Information Governance Center, Siksika, Alberta, Canada (L. Bill)

DOI: https://doi.org/10.3201/eid2702.201945 region; pharyngitis is more common in high-income countries, and diseases such as impetigo are more common in tropical climates and low-income countries $(3,4)$. In 2005, the mortality rate associated with GAS disease (noninvasive and invasive) was $\approx 500,000$ deaths/year (2).

GAS bacteria can be typed by identifying variability in the DNA sequence at the tip of a coiled-coil protein on the bacteria's surface (the M protein), which is encoded by the emm gene. Worldwide, there are $>240 \mathrm{emm}$ types $(5,6)$. Prevalence of $\mathrm{emm}$ types varies according to population and geography (7). In addition, the diversity of emm types is greater in developing countries and less in more developed countries $(8-10)$.

Previous studies have shown that rates of iGAS disease are higher for indigenous populations than for other populations (11-15). Examples include Native Americans in Arizona and Alaska and indigenous communities in parts of Australia and northwestern Ontario, Canada. For parts of the country such as western Canada, detailed descriptive data on iGAS in the indigenous population are lacking. We previously reported increased age-standardized rates of iGAS in Alberta's general population and increasing incidence from a low of 4.2 cases $/ 100,000$ persons in 2003 to a high of 10.2 cases/100,000 persons in 2017 (16). On the basis of that finding, we explored whether iGAS rates also increased for the First Nations population of Alberta during the same period.

\section{Methods}

\section{Case and Population Data}

All iGAS cases were identified by diagnostic microbiology laboratories in Alberta, where iGAS disease is listed as a Public Health Notifiable Disease (https:/ / open.alberta.ca/publications/streptococcal-disease- 
group-a-invasive). All cases identified by diagnostic microbiology laboratories are required to be reported to the Alberta Ministry of Health. Confirmed iGAS cases are defined as identification of GAS from any typically sterile site, including blood, cerebrospinal fluid, brain, deep tissues, and joints (https:/ / open.alberta.ca/publications/streptococcal-disease-groupa-invasive). After initially identifying iGAS isolates, diagnostic microbiology laboratories in Alberta informed provincial public health officials, and trained public health nurses collected clinical and risk factor data according to routine notifiable disease requirements by using a notifiable disease reporting form (https://open.alberta.ca/publications/ndr-manual-9th-edition). Clinical (including risk factors) and laboratory data were electronically captured in the Alberta Health Communicable Disease Reporting System (CDRS), an electronic database held by Alberta Health and used to capture data regarding cases of reported communicable disease. Staff at Alberta Health reviewed each incident case for data quality and completeness in the CDRS.

For the risk factor analysis, we defined addiction abuse as a primary chronic neurobiological disease with genetic, psychosocial, and environmental factors and behaviors leading to impaired control over drug use, compulsive use, continued use despite harm, and craving. Subsets of addiction abuse were alcohol abuse and drug use. Alcohol abuse was defined as the overindulgence in alcohol, leading to effects that are detrimental to the person's physical and mental health. Drug use was defined as the use of all drugs that were acquired unlawfully. Deaths were determined at the time of data collection by Alberta Health.

In Canada, there are 3 groups of aboriginal peoples: First Nations, Inuit, and Métis (https:/ /www. rcaanc-cirnac.gc.ca/eng/1100100013785/1529102490 303). Only cases in First Nations persons, Inuit, and Métis were captured in this analysis. To identify cases in First Nations persons only, we extracted all iGAS cases during 2003-2017 from the CDRS and used a Unique Lifetime Identifier number to link them to the Alberta Health First Nations identifiers registry held by Alberta Health. The First Nations registry includes anyone ever registered as having First Nations status. For statistical analyses, we used deidentified and aggregated data. The First Nations population of Alberta in 2003 was 140,436; in 2017, the population was 164,786 (http:/ / www.ahw.gov.ab.ca/IHDA_Retrieval). An ethical framework for information and knowledge-sharing for this project was provided by the principles of OCAP (Ownership, Control, Access and Possession) within Alberta First Nations (http:/ / afnigc.ca/main/index.php?id=resources\&co ntent $=$ community $\%$ 20resources).

\section{emm Typing of iGAS Isolates}

All GAS isolates from persons with invasive cases are required to be submitted to the Provincial Public Health Laboratory for emm typing. The method used to type iGAS isolates from 2003 through September 2006 was a previously described serologic typing assay (17). From October 2006 through 2017, emm typing was conducted by DNA sequencing of the M serotype specific region of the $\mathrm{emm}$ gene as previously described (17-19). Assignment of emm-cluster type was performed as previously described (20). In brief, after the emm type was identified, it was matched to an emm-cluster type on the basis of the typing scheme of Sanderson-Smith et al. (20).

\section{Statistical Analyses}

During 2003-2017, First Nations population estimates in Alberta were extracted from the online Interactive Health Data Application database (http:/ / www.ahw.gov.ab.ca/IHDA_Retrieval). We calculated incidence rates by age group and by year of diagnosis, expressed as cases per 100,000 persons. Data were analyzed by using SAS version 9.3 (SAS Institute Inc., https:/ /www.sas.com) and graphed by using OriginLab software 2018 (OriginLab Corporation, https://www.originlab.com). To compare clinical presentations and emm clusters between First Nations and non-First Nations persons, we conducted Fisher exact $t$ tests. We considered $\mathrm{p}<0.05$ to be statistically significant.

\section{Results}

\section{Incidence}

Over the 15 years reviewed, we found 669 cases of iGAS in the First Nations population in Alberta; mean annual incidence rate was 28.6 cases $/ 100,000$ persons. The number of cases in 2003 was 14, which by 2017 increased to 86. In 2017, the incidence rate for the Alberta First Nations population (52.2 cases/100,000 persons) was 6 times greater than that for non-First Nations populations (8.7 cases/100,000 persons) (Figure 1). By First Nations age group, incidence was highest among persons $<1$ year of age $(71.2$ cases $/ 100,000$ persons), followed by persons $\geq 60$ years of age $(65.8$ cases $/ 100,000$ persons) (Figure 2, panel A). iGAS incidence among First Nations persons of all age groups was higher than that among non-First Nations persons (Figure 2). Incidence rates varied by season; the number of cases of iGAS among First Nations persons was 


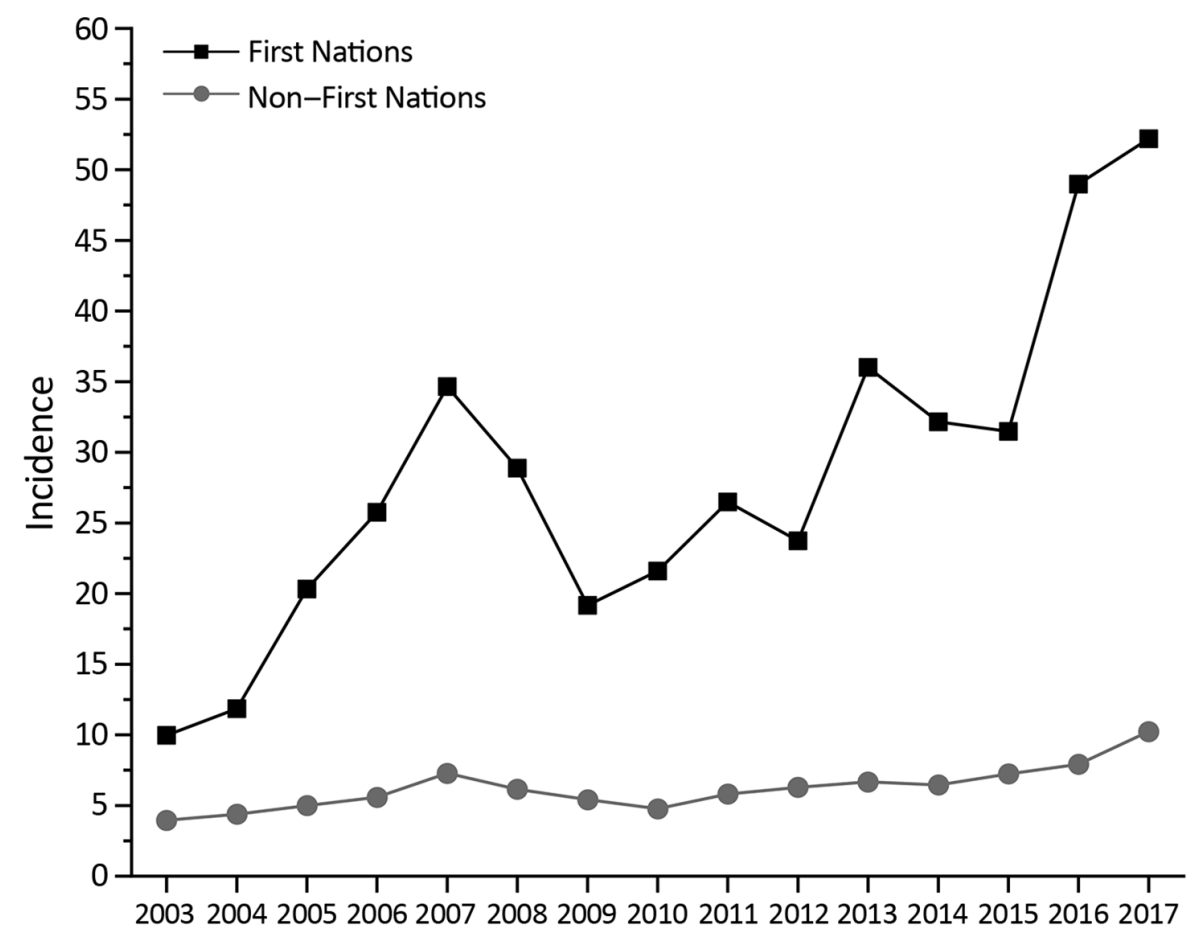

Figure 1. Incidence (cases/100,000 population) of invasive group A Streptococcus disease for First Nations and non--First Nations populations, Alberta, Canada, 20032017. The incidence rate for the First Nations population climbed from a low of 10.0 in 2003 to a high of 52.2 in 2017. This rate contrasts with that for the non-First Nations population (3.7 in 2003 and 8.7 in 2017). lowest during May and June (Figure 3), similar to what has been reported for the general population (16).

\section{Case Demographics, Clinical Manifestations, and Risk Factor Analyses}

The median age of First Nations persons with iGAS disease was 38.5 years, younger than the overall median age of 45 years for persons with iGAS disease previously reported for the overall Alberta population (16). The proportion of First Nations iGAS patients who were male $(54.8 \%)$ was similar to the proportion of non-First Nations patients who were male (58.5\%). A total of 24 deaths among First Nations patients were attributed to iGAS; case-fatality rate was 3.6\%. In comparison, the case-fatality rate among non-First Nations persons was $7.0 \%$. By age group, of the 24 First Nations persons who died, 2 were children $(<1$ through 2 years of age). The remaining 22 First Nations persons who died were $\geq 35$ years of age (Figure 2 , panel A). For all age groups, case-fatality rates were higher among non-First Nations than among First Nations persons (Figure 2, panels A and B).

We observed little difference between First Nations and non-First Nations populations with respect to clinical diagnosis (Table 1). The percentage of soft tissue infections was higher for the First Nations population

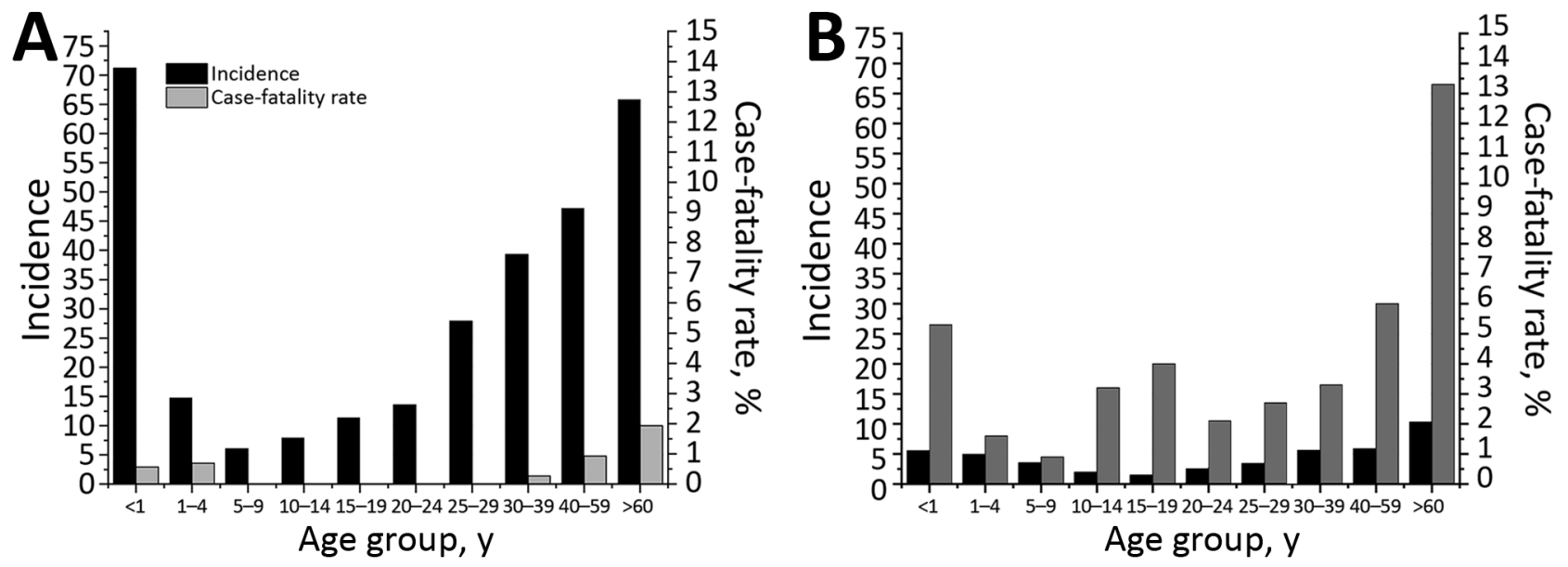

Figure 2. Incidence (cases/100,000 population) and case-fatality rates for invasive group A Streptococcus disease for First Nations (A) and non-First Nations (B) populations, by age group, Alberta, Canada, 2003-2017. 


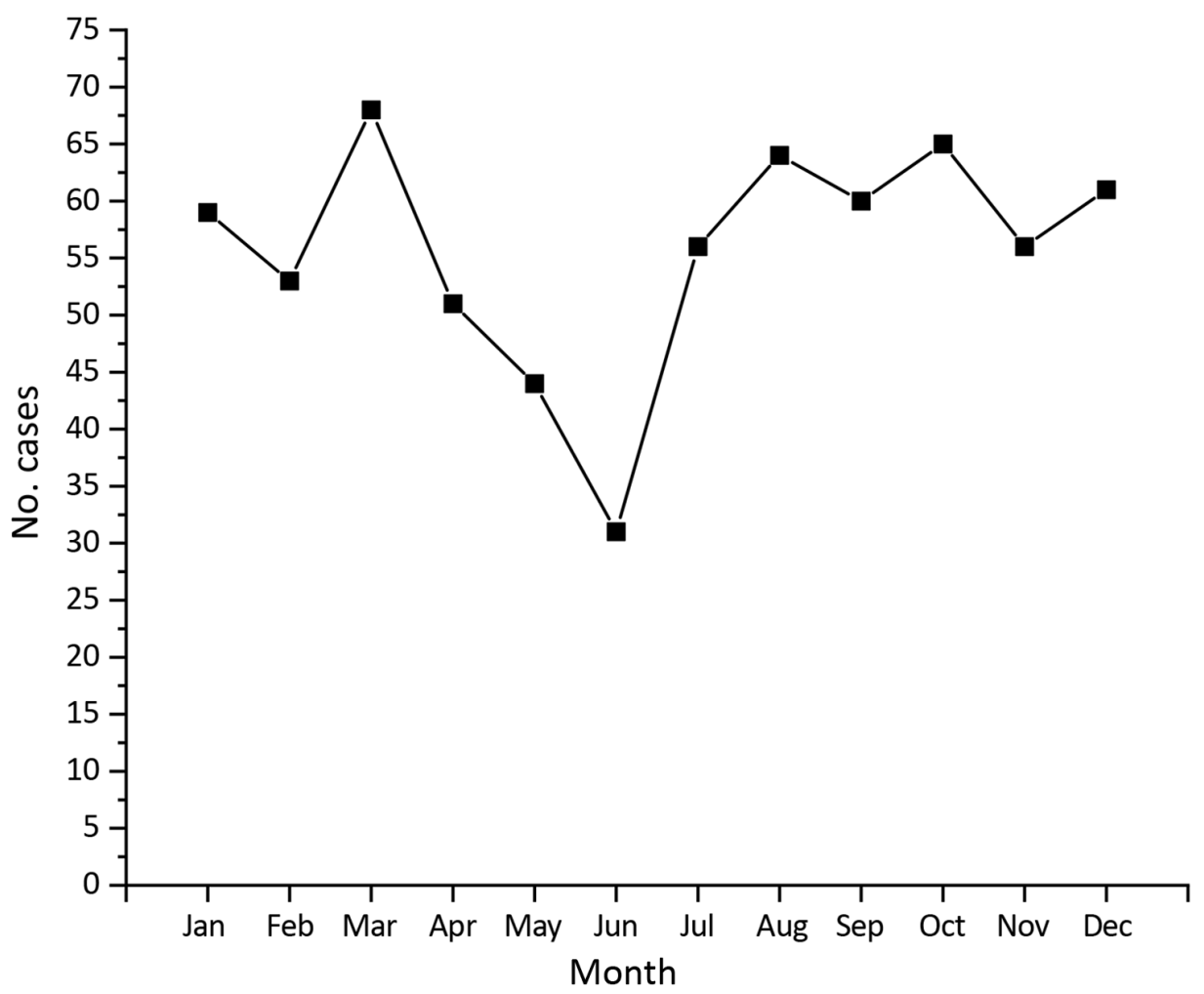

Figure 3. Seasonality of invasive group A Streptococcus disease in the First Nations population, Alberta, Canada, 2003-2017.

than the non-First Nations population (18.8\% vs. $10.8 \%$, $\mathrm{p}<0.001$; Table 1). Frequency of streptococcal toxic shock syndrome was greater in the non-First Nations population than in the First Nations population (6.4\% vs. $2.3 \%$, $p<0.001 ;$ Table 1). The most prevalent risk factors for the First Nations population over the 15-year study period were addiction abuse, alcohol abuse, drug use, nonsurgical wounds, homelessness, diabetes mellitus, and hepatitis C (16) (Table 2). emm Types and emm Cluster Descriptions

For the 15-year study period, we observed a difference in the distribution of emm types between First Nations and non-First Nations populations in Alberta. The most prevalent emm type among the First Nations population was emm59, which accounted for $13.5 \%$ of all $\mathrm{emm}$ types, followed by emm101 (8.4\%) and $82(7.4 \%)$ (Table 3, Figure 4). This finding was in contrast to that for the non-First Nations population,

\begin{tabular}{|c|c|c|c|}
\hline System, clinical condition & First Nations, no. (\%) cases & Non-First Nations, no. (\%) cases & $\mathrm{p}$ value \\
\hline \multicolumn{4}{|l|}{ Blood, brain, sterile tissue } \\
\hline Septicemia/bacteremia & $319(37.8)$ & $1570(42.8)$ & 0.011 \\
\hline Streptococcal toxic shock syndrome & $19(2.3)$ & $235(6.4)$ & $<0.001$ \\
\hline Meningitis & $9(1.1)$ & $16(0.4)$ & 0.061 \\
\hline Peritonitis & $5(0.6)$ & $24(0.7)$ & 0.886 \\
\hline Encephalitis & $1(0.1)$ & 0 & 0.373 \\
\hline \multicolumn{4}{|l|}{ Skin/soft tissue } \\
\hline Cellulitis & $146(17.3)$ & $633(17.3)$ & 0.971 \\
\hline Soft tissue infection & $159(18.8)$ & $397(10.8)$ & $<0.001$ \\
\hline Necrotizing fasciitis & $60(7.1)$ & $266(7.3)$ & 0.989 \\
\hline \multicolumn{4}{|l|}{ Respiratory } \\
\hline Pneumonia & $50(5.9)$ & $291(7.9)$ & 0.054 \\
\hline Epiglottitis & $2(0.2)$ & $11(0.3)$ & 0.824 \\
\hline \multicolumn{4}{|l|}{ Bone } \\
\hline Joint & $63(7.5)$ & $192(5.2)$ & 0.016 \\
\hline Osteomyelitis & $10(1.2)$ & $27(0.8)$ & 0.272 \\
\hline Unknown & $2(0.2)$ & 0 & 0.069 \\
\hline Total & $845(100)$ & $3,688(100)$ & Not applicable \\
\hline
\end{tabular}


for which the top $3 \mathrm{emm}$ types were $\mathrm{emm} 1$ (22.1\%), 28 $(9.9 \%), 3(5.1 \%)$, and 59 (5.1\%).

emm cluster types differed substantially between First Nations and non-First Nations populations (Table 4). These differences were notable for cluster types A-C3, D4, E3, E4, and E6. The cluster types associated with the greatest number of cases for the First Nations population were D4 (emm41, 53, 80, 83, 91, 101) and E6 (emm11, 59, 75, 81, 94), representing $50.6 \%$ of the cases in this group. Twelve other clusters represented the remaining $49.4 \%$ (30 other $\mathrm{emm}$ types) of typed cases.

\section{Discussion}

Our data illustrate the extent to which rates of iGAS disease are disproportionately higher for the First Nations population than the non-First Nations population in Alberta. For 2017, rates for the First Nations population (52.2 cases/100,000 persons) were 6-fold higher than rates for non-First Nations populations (8.7 cases/100,000 persons). Rates were also very high for First Nations children $<1$ year of age $(71.2$ cases $/ 100,000$ persons), in contrast to previously published rates for children in the 0 to 1 -year age group of the general Alberta population (9.7 cases/100,000 persons [16]). Our results are similar to those reported for First Nations groups elsewhere. For example, another study in Canada found that, from 2009 through 2014, northwestern Ontario reported an elevated annualized rate of 56.2 cases $/ 100,000$ persons for the First Nations communities (14), similar to the rates we report for First Nations populations. With respect to other indigenous groups elsewhere, iGAS rates for the Aboriginal population in Australia during 2011-2013 were as high as
Table 2. Risk factors for First Nations and non-First Nations persons with invasive group A Streptococcus disease, Alberta, Canada, 2003-2017*

\begin{tabular}{lcc}
\hline & \multicolumn{2}{c}{ No. (\%) } \\
\cline { 2 - 3 } Risk factor & $\begin{array}{c}\text { First Nations, } \mathrm{n} \\
\text { Non-First Nations, } \\
\mathrm{n}=669\end{array}$ & $\mathrm{n}=2,315$ \\
\hline Diabetes & $103(15.4)$ & $176(7.6)$ \\
Hepatitis C & $101(15.1)$ & $181(7.8)$ \\
Immunocompromised & $41(6.1)$ & $238(10.3)$ \\
Nonsurgical wound & $165(24.7)$ & $543(23.5)$ \\
Surgical wound & $43(6.4)$ & $133(5.7)$ \\
\hline Addiction abuse & $250(37.4)$ & $390(16.8)$ \\
$\quad$ Alcohol abuse & $188(28.1)$ & $90(3.9)$ \\
$\quad$ Drug use & $126(18.8)$ & $307(13.3)$ \\
\hline Homelessness & $117(17.5)$ & $257(11.1)$ \\
\hline *Percentages may add up to $>100 \%$ because each patient may have & \multicolumn{2}{c}{} \\
multiple risk factors. &
\end{tabular}

70.0 cases $/ 100,000$ persons, 8 -fold higher than rates for the non-Aboriginal population (21). A previous study from Alaska found that during 2001-2013, the incidence rate for Alaska Natives was 13.7 cases/100,000 persons, compared with a rate of 3.9 cases $/ 100,000$ persons for non-Alaska Natives (15). Reported rates for Alaska Native children (39.9 cases/100,000 persons) have been higher than those reported for non-Alaska Native children (4.2 cases/100,000 persons) (15).

Drivers of the higher rates in the First Nations populations are not completely clear, although specific risk factors probably contribute. Risk factor data for iGAS in the First Nations population in our study frequently indicated nonsurgical wounds, addiction abuse (of which alcohol use and drug use are subsets), and homelessness. Other studies have noted high rates of GAS skin infections (e.g., cellulitis and abscesses) among persons who were experiencing homelessness and injected drugs (22-24). Recently,

\begin{tabular}{|c|c|c|c|c|c|c|c|c|c|c|c|c|c|c|c|c|}
\hline emm type & 2003 & 2004 & 2005 & 2006 & 2007 & 2008 & 2009 & 2010 & 2011 & 2012 & 2013 & 2014 & 2015 & 2016 & 2017 & Total \\
\hline 59 & 0 & 0 & 1 & 0 & 7 & 18 & 12 & 4 & 3 & 1 & 3 & 1 & 4 & 10 & 13 & 77 \\
\hline 101 & 0 & 0 & 0 & 0 & 0 & 1 & 4 & 1 & 4 & 2 & 1 & 2 & 9 & 14 & 10 & 48 \\
\hline 82 & 1 & 3 & 0 & 3 & 7 & 2 & 1 & 0 & 2 & 3 & 6 & 2 & 2 & 7 & 3 & 42 \\
\hline 41 & 1 & 1 & 4 & 2 & 2 & 1 & 0 & 0 & 0 & 3 & 3 & 11 & 4 & 4 & 2 & 38 \\
\hline 11 & 0 & 0 & 0 & 2 & 0 & 0 & 0 & 0 & 2 & 5 & 3 & 0 & 5 & 9 & 11 & 37 \\
\hline 1 & 0 & 1 & 1 & 1 & 4 & 2 & 1 & 2 & 3 & 1 & 5 & 5 & 1 & 0 & 4 & 31 \\
\hline 83 & 0 & 1 & 2 & 2 & 6 & 2 & 0 & 0 & 1 & 3 & 1 & 1 & 2 & 3 & 5 & 29 \\
\hline 77 & 0 & 1 & 0 & 1 & 0 & 0 & 1 & 2 & 2 & 5 & 11 & 2 & 0 & 0 & 1 & 26 \\
\hline 53 & 0 & 0 & 0 & 2 & 2 & 1 & 2 & 2 & 5 & 1 & 5 & 3 & 0 & 0 & 0 & 23 \\
\hline 74 & 0 & 0 & 0 & 0 & 0 & 0 & 0 & 0 & 0 & 0 & 0 & 0 & 0 & 5 & 17 & 22 \\
\hline 89 & 0 & 0 & 2 & 1 & 2 & 0 & 1 & 2 & 4 & 0 & 1 & 1 & 1 & 0 & 1 & 16 \\
\hline 91 & 0 & 0 & 0 & 3 & 1 & 0 & 0 & 0 & 1 & 2 & 3 & 1 & 3 & 2 & 0 & 16 \\
\hline 12 & 0 & 0 & 1 & 1 & 1 & 0 & 0 & 2 & 4 & 0 & 1 & 0 & 1 & 3 & 1 & 15 \\
\hline 114 & 0 & 2 & 1 & 2 & 3 & 0 & 0 & 2 & 1 & 0 & 0 & 2 & 1 & 0 & 0 & 14 \\
\hline 3 & 1 & 0 & 0 & 1 & 1 & 0 & 0 & 0 & 1 & 0 & 0 & 0 & 5 & 3 & 0 & 12 \\
\hline 22 & 1 & 0 & 0 & 0 & 0 & 0 & 0 & 2 & 0 & 0 & 2 & 3 & 1 & 2 & 1 & 12 \\
\hline 87 & 0 & 0 & 0 & 1 & 1 & 0 & 0 & 2 & 3 & 0 & 1 & 2 & 1 & 1 & 0 & 12 \\
\hline 80 & 0 & 0 & 1 & 0 & 0 & 4 & 0 & 2 & 1 & 1 & 2 & 0 & 0 & 1 & 0 & 12 \\
\hline Other & 4 & 3 & 7 & 5 & 6 & 4 & 3 & 3 & 3 & 3 & 4 & 5 & 3 & 9 & 11 & 73 \\
\hline Nontypable & 2 & 4 & 2 & 6 & 0 & 1 & 0 & 0 & 0 & 0 & 0 & 0 & 0 & 0 & 0 & 15 \\
\hline Total & 10 & 16 & 22 & 33 & 43 & 36 & 25 & 26 & 40 & 30 & 52 & 41 & 43 & 73 & 80 & 570 \\
\hline
\end{tabular}


work by the Active Bacterial Core surveillance program in the United States showed that skin infections and skin breakdown were common among iGAS patients who were injection drug users or experiencing homelessness (25). These studies suggest that skin infections in vulnerable populations with these risk factors provide routes for iGAS infections.

A role of skin infections is also suggested when emm types are grouped by emm clusters. Grouping emm types by cluster shows that the bulk of disease among the First Nations population was focused on cluster emm types that are considered to be associated with skin-related infections (D clusters) and generalist strains (E clusters), as opposed to throat-related clusters (A-C) (26). This finding may suggest that in this population, skin-to-skin transmission occurs more frequently than respiratory route transmission. Opportunities for skin-to-skin transmission can include overcrowded households, as has been documented in Australia for the Aboriginal population, in whom the high burden of iGAS disease associated with skin and soft tissue infections is related to overcrowded or inadequate housing $(27,28)$. With respect to other potential risk factors, risk for iGAS has been found to be significantly increased for close contacts of iGAS patients $(\approx 2,000$ times higher than background incidence) $(29,30)$. Overcrowding and inadequate housing have also been documented among First Nations

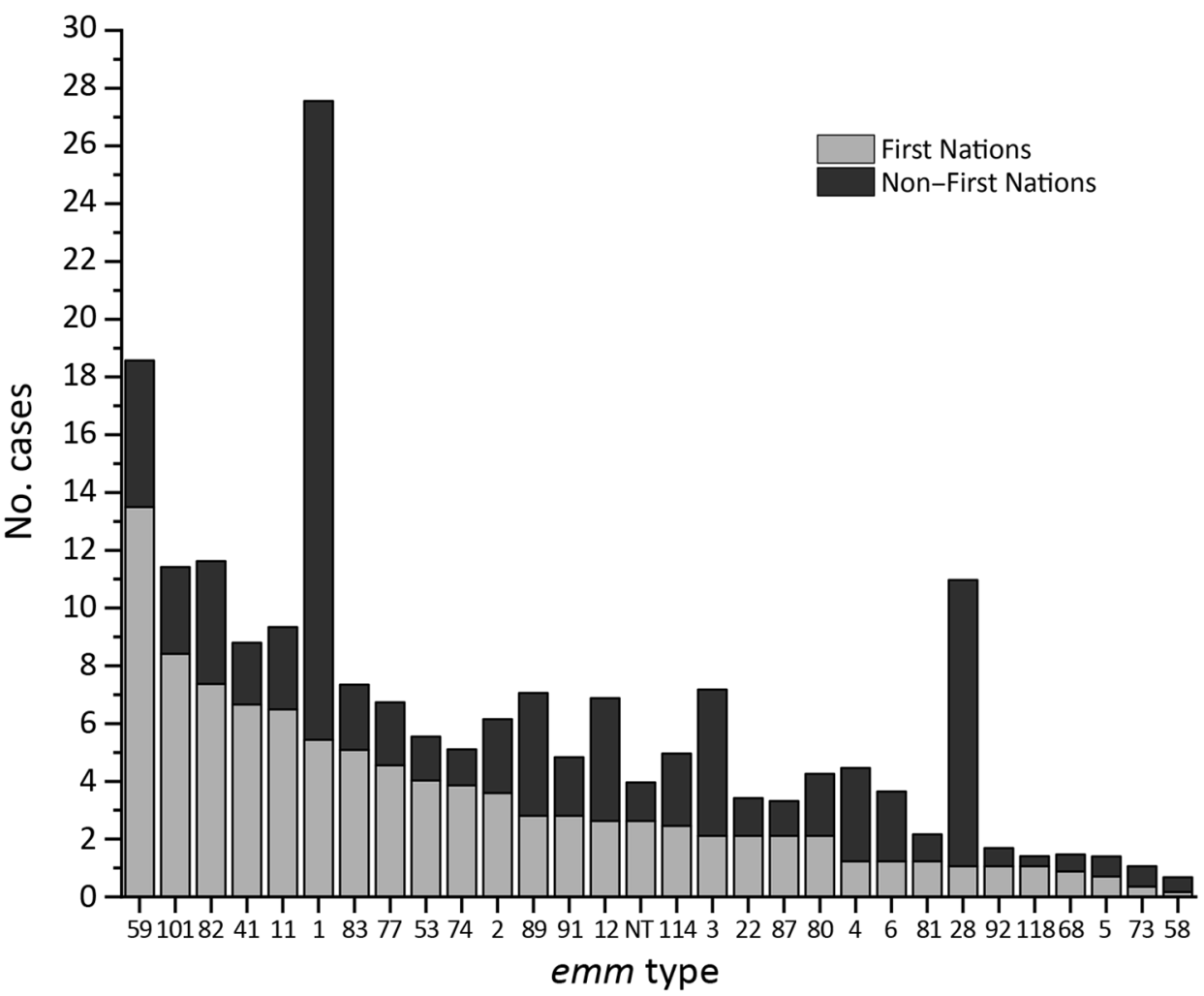

populations in Canada (31). Overcrowding has been considered endemic to First Nations populations in Canada and can probably lead to higher rates of disease than in non-First Nations populations (31). However, the numbers of persons living in households was not a demographic captured in this study; therefore, whether overcrowding was a contributor for this study remains unclear.

When we examined specific clinical conditions, we found additional contrasts in iGAS disease between First Nations and non-First Nations groups. Soft tissue and joint infections occurred with more statistically significant frequency in the First Nations population than in the non-First Nations population, whereas septicemia/bacteremia and streptococcal toxic shock syndrome occurred with more frequency in the non-First Nations population than in the First Nations population. The reasons for these differences are not clear and may be multifactorial. We did not expect to find that streptococcal toxic shock syndrome occurred more frequently in the non-First Nations population. A different $\mathrm{emm}$ type distribution may account for some of these differences.

Prevalence of $\mathrm{emm} 1$ was greater for the non-First Nations population $(>22 \%)$ than for the First Nations population $(<6 \%)$. emm 1 is a major contributor to streptococcal toxic shock syndrome and is the most frequent $\mathrm{emm}$ type isolated from persons in the

Figure 4. Group A Streptococcus emm types from First Nations persons and non-First Nations with invasive disease, Alberta, Canada, 2003-2017. 
Table 4. emm clusters among group A Streptococcus from First Nations and non-First Nation persons with invasive disease, Alberta, Canada, 2003-2017

\begin{tabular}{|c|c|c|c|c|}
\hline Cluster type & First Nations, no. (\%) & Non-First Nations, no. (\%) & Total cases & $p$ value \\
\hline $\mathrm{A}-\mathrm{C} 3$ & $32(5.8)$ & $568(22.7)$ & 600 & $<0.001$ \\
\hline $\mathrm{A}-\mathrm{C} 4$ & $15(2.7)$ & $141(5.6)$ & 156 & 0.004 \\
\hline A-C5 & $12(2.2)$ & $130(5.2)$ & 142 & 0.001 \\
\hline D2 & $1(0.2)$ & $2(0.1)$ & 3 & 0.902 \\
\hline D3 & 0 & $3(0.2)$ & 3 & 0.948 \\
\hline D4 & $166(30.0)$ & $310(12.4)$ & 476 & $<0.001$ \\
\hline E1 & $7(1.3)$ & $83(3.1)$ & 90 & 0.008 \\
\hline E2 & $18(3.3)$ & $64(2.6)$ & 82 & 0.435 \\
\hline E3 & 65 (11.7) & $199(8.0)$ & 264 & 0.007 \\
\hline E4 & 79 (14.3) & $616(24.6)$ & 695 & $<0.001$ \\
\hline E5 & 0 & $5(0.2)$ & 5 & 0.736 \\
\hline E6 & $125(22.6)$ & $268(10.7)$ & 393 & $<0.001$ \\
\hline M5 & $4(0.7)$ & $18(0.7)$ & 22 & 0.787 \\
\hline M6 & $7(1.3)$ & $62(2.5)$ & 69 & 0.100 \\
\hline M23 & $1(0.2)$ & 0 & 1 & 0.362 \\
\hline M74 & $22(4.0)$ & $32(1.3)$ & 54 & $<0.001$ \\
\hline M111 & 0 & $1(0.1)$ & 1 & 0.408 \\
\hline M122 & 0 & $1(0.1)$ & 1 & 0.408 \\
\hline M218 & 0 & $1(0.1)$ & 1 & 0.408 \\
\hline Total & $554(100)$ & $2,504(100)$ & 3,058 & Not applicable \\
\hline
\end{tabular}

non-First Nations population in Alberta $(16,32)$. The reason(s) behind the decreased presence of emm 1 in the First Nations population despite it being the dominant emm type in the non-First Nations population are not clear.

In contrast to the lower frequency of streptococcal toxic shock syndrome is the higher frequency of soft tissue infections in the First Nations population. Our data show that emm59 was the most prevalent emm type in the First Nations population, and it has previously been shown that emm59 displays a tropism for skin infections $(33,34)$. Since 2006 , when a large outbreak of emm59 was first reported, emm59 has become an established emm type causing diseases such as skin and soft tissue infections throughout western Canada and the United States, whereas previously it was relatively rare (33,35-37). The emm59 cases reported here are probably derived from that original outbreak in 2006-2009 because before then, emm59 was uncommon.

Also notable is the striking difference in percentage of $e m m 28$ cases between First Nations ( $\approx 1 \%$ ) versus non-First Nations ( $\approx 10 \%)$ populations. Our previous survey of the overall population indicated that emm 28 was the second most common emm type after emm 1 (16). emm 28 falls within the E4 cluster categorizing this emm type as a generalist (20). The reason for the large difference in emm 28 prevalence between the 2 populations is not clear.

The high iGAS incidence rate in the Alberta First Nations population illustrates the need for an effective GAS vaccine. One vaccine that has undergone phase 1 clinical trials is a polypeptide vaccine composed of $30 \mathrm{emm}$ types (38). An assessment of the $\mathrm{emm}$ types contained in this 30-valent M protein-based GAS vaccine shows that this vaccine would include $\approx 53 \%$ of the $\mathrm{emm}$ types found in the Alberta First Nations population (38). If cross-protection against nonvaccine emm types based on immunogenicity in rabbits were included, this coverage rate would increase to $62.3 \%$ (38). In comparison, the 30 -valent $\mathrm{M}$ protein-based vaccine would include $77.1 \%$ of the emm types found in the non-First Nations population; if cross-protection with non-vaccine $\mathrm{emm}$ types were included, this percentage would increase to $79.8 \%$. These comparisons do not include potential crossprotection through coverage of emm clusters. These emm type differences would have to be taken into account for the First Nations population should an emm type-based vaccine such as this be introduced into the Alberta population.

In summary, iGAS rates in the First Nations community in Alberta are high, at $\approx 50$ cases $/ 100,000$ persons. Marked differences in iGAS disease in the First Nations population include more skin and soft tissue infections and fewer streptococcal toxic shock syndrome cases than in the non-First Nations population. Of note, substantial $\mathrm{emm}$ differences between the 2 populations could have potential implications for future vaccines.

\section{Acknowledgments}

We thank the clinical diagnostic microbiology laboratories in Alberta for identifying iGAS isolates and submitting these to the Provincial Public Health Laboratory for emm typing.

This work was supported by Alberta Health and Alberta Precision Laboratories-Public Health, Alberta Health 
Services, and the AMR-One Health Consortium Major Innovation Fund program of the Ministry of Jobs, Economy and Innovation, government of Alberta.

\section{About the Author}

Dr. Tyrrell is a professor and divisional director in the Division of Diagnostic and Applied Microbiology, Department of Laboratory Medicine and Pathology, University of Alberta, Edmonton. His primary research interests are epidemiology of GAS, Streptococcus pneumoniae, and pathogenesis of group B streptococci.

\section{References}

1. Cunningham MW. Pathogenesis of group A streptococcal infections. Clin Microbiol Rev. 2000;13:470-511. https://doi.org/10.1128/CMR.13.3.470

2. Carapetis JR, Steer AC, Mulholland EK, Weber M. The global burden of group A streptococcal diseases. Lancet Infect Dis. 2005;5:685-94. https:/ / doi.org/10.1016/ S1473-3099(05)70267-X

3. Bowen AC, Tong SYC, Chatfield MD, Carapetis JR. The microbiology of impetigo in indigenous children: associations between Streptococcus pyogenes, Staphylococcus aureus, scabies, and nasal carriage. BMC Infect Dis. 2014;14:727. https://doi.org/10.1186/s12879-014-0727-5

4. Steer AC, Jenney AWJ, Kado J, Batzloff MR, La Vincente S, Waqatakirewa L, et al. High burden of impetigo and scabies in a tropical country. PLoS Negl Trop Dis. 2009;3:e467. https:/ / doi.org/10.1371/journal.pntd.0000467

5. Bessen DE, Smeesters PR, Beall BW. Molecular epidemiology, ecology and evolution of group A streptococci. Microbiol Spec. 2018;6. https://doi.org/10.1128/microbiolspec. CPP3-0009-2018

6. Centers for Disease Control and Prevention. Streptococcus pyogenes (group A Streptococcus) [cited 2019 Oct 19]. https://www.cdc.gov/streplab/groupa-strep/index.html

7. Steer AC, Law I, Matatolu L, Beall BW, Carapetis JR. Global emm type distribution of group A streptococci: systematic review and implications for vaccine development. Lancet Infect Dis. 2009;9:611-6. https://doi.org/10.1016/ S1473-3099(09)70178-1

8. Tewodros W, Kronvall G. M protein gene (emm type) analysis of group A beta-hemolytic streptococci from Ethiopia reveals unique patterns. J Clin Microbiol. 2005;43:4369_ 76. https://doi.org/10.1128/JCM.43.9.4369-4376.2005

9. Smeesters PR, Vergison A, Campos D, de Aguiar E, Miendje Deyi VY, Van Melderen L. Differences between Belgian and Brazilian group A Streptococcus epidemiologic landscape. PLoS One. 2006;1:e10. https://doi.org/10.1371/ journal.pone. 0000010

10. Sakota V, Fry AM, Lietman TM, Facklam RR, Li Z, Beall B. Genetically diverse group A streptococci from children in far-western Nepal share high genetic relatedness with isolates from other countries. J Clin Microbiol. 2006;44:21606. https://doi.org/10.1128/JCM.02456-05

11. Hoge CW, Schwartz B, Talkington DF, Breiman RF, MacNeill EM, Englender SJ. The changing epidemiology of invasive group A streptococcal infections and the emergence of streptococcal toxic shock-like syndrome. A retrospective population-based study. JAMA. 1993;269:384-9. https://doi.org/10.1001/jama.1993.03500030082037
12. Marshall CS, Cheng AC, Markey PG, Towers RJ, Richardson LJ, Fagan PK, et al. Acute post-streptococcal glomerulonephritis in the Northern Territory of Australia: a review of 16 years data and comparison with the literature. Am J Trop Med Hyg. 2011;85:703-10. https://doi.org/10.4269/ajtmh.2011.11-0185

13. Harris AM, Yazzie D, Antone-Nez R, Dinè-Chacon G, Kinlacheeny JB, Foley D, et al. Community-acquired invasive GAS disease among Native Americans, Arizona, USA, Winter 2013. Emerg Infect Dis. 2015;21:177-9. https://doi.org/10.3201/eid2101.141148

14. Bocking N, Matsumoto C, Loewen K, Teatero S, MarchandAustin A, Gordon J, et al. High incidence of invasive group A streptococcal infections in remote First Nations communities in Northwestern Ontario, Canada. Open Forum Infect Dis. 2016 ;4:ofw243. https://doi.org/10.1093/ofid/ofw243

15. Rudolph K, Bruce MG, Bruden D, Zulz T, Reasonover A, Hurlburt D, et al. Epidemiology of invasive group A streptococca 1 disease in Alaska, 2001-2013. J Clin Microbiol. 2016;54:134-41. https://doi.org/10.1128/JCM.02122-15

16. Tyrrell GJ, Fathima S, Kakulphimp J, Bell C. Increasing rates of invasive group A streptococcal disease in Alberta, Canada, 2003-2017. Open Forum Infect Dis. 2018;5:ofy177. https://doi.org/10.1093/ofid/ofy177

17. Tyrrell GJ, Lovgren M, Kress B, Grimsrud K. Invasive group A streptococcal disease in Alberta, Canada (2000 to 2002). J Clin Microbiol. 2005;43:1678-83. https:/ / doi.org/10.1128/ JCM.43.4.1678-1683.2005

18. Centers for Disease Control and Prevention. Protocol for emm typing [cited 2020 Feb 7]. https:/ / www.cdc.gov/streplab/ protocol-emm-type.html

19. Centers for Disease Control and Prevention. Streptococcus pyogenes emm sequence database, 2018 [cited 2020 Mar 1]. https://www.cdc.gov/streplab/groupa-strep/emm-typingprotocol.html

20. Sanderson-Smith M, De Oliveira DMP, Guglielmini J, McMillan DJ, Vu T, Holien JK, et al.; M Protein Study Group. A systematic and functional classification of Streptococcus pyogenes that serves as a new tool for molecular typing and vaccine development. J Infect Dis. 2014;210:1325-38. https:/ / doi.org/10.1093/infdis/jiu260

21. Boyd R, Patel M, Currie BJ, Holt DC, Harris T, Krause V. High burden of invasive group A streptococcal disease in the Northern Territory of Australia. Epidemiol Infect. 2016;144:1018-27. https://doi.org/10.1017/ S0950268815002010

22. Gittzus JWJ, White J, Caine L, Hansen K, Daly E, Chan B, et al. An outbreak of invasive group A streptococcal infections in injection drug users. Open Forum Infect Dis. 2017;4(suppl_1):S241. https://doi.org/10.1093/ofid/ ofx163.511

23. Bundle N, Bubba L, Coelho J, Kwiatkowska R, Cloke R, King S, et al. Ongoing outbreak of invasive and non-invasive disease due to group A Streptococcus (GAS) type emm66 among homeless and people who inject drugs in England and Wales, January to December 2016. Euro Surveill. 2017;22:1-6. https:// doi.org/10.2807/1560-7917.ES.2017.22.3.30446

24. Dickson C, Pham MT, Nguyen V, Brubacher C, Silverman MS, Khaled K, et al. Community outbreak of invasive group A streptococcus infection in Ontario, Canada. Can Commun Dis Rep. 2018;44:182-8. https://doi.org/10.14745/ccdr.v44i78a06

25. Valenciano SJ, Onukwube J, Spiller MW, Thomas A, Como-Sabetti K, Schaffner W, et al. Invasive group A streptococcal infections among people who inject drugs and people experiencing homelessness in the United States, 
2010-2017. Clin Infect Dis. 2020:ciaa787. https:/ / doi.org/ in10.1093/cid/ciaa787

26. McMillan DJ, Drèze P-A, Vu T, Bessen DE, Guglielmini J, Steer AC, et al. Updated model of group A Streptococcus M proteins based on a comprehensive worldwide study. Clin Microbiol Infect. 2013;19:E222-9. https://doi.org/10.1111/ 1469-0691.12134

27. Steer AC, Carapetis JR, Nolan TM, Shann F. Systematic review of rheumatic heart disease prevalence in children in developing countries: the role of environmental factors. J Paediatr Child Health. 2002;38:229-34. https:// doi.org/10.1046/j.1440-1754.2002.00772.x

28. Jaine R, Baker M, Venugopal K. Acute rheumatic fever associated with household crowding in a developed country. Pediatr Infect Dis J. 2011;30:315-9. https:/ / doi.org/10.1097/ INF.0b013e3181fbd85b

29. O'Grady KA, Kelpie L, Andrews RM, Curtis N, Nolan TM, Selvaraj G, et al. The epidemiology of invasive group A streptococcal disease in Victoria, Australia. Med J Aust. 2007;186:565-9. https://doi.org/10.5694/j.1326-5377.2007. tb01054.x

30. Mearkle R, Saavedra-Campos M, Lamagni T, Usdin M, Coelho J, Chalker V, et al. Household transmission of invasive group A Streptococcus infections in England: a populationbased study, 2009, 2011 to 2013. Euro Surveill. 2017;22:30532. https://doi.org/10.2807/1560-7917.ES.2017.22.19.30532

31. Anaya J. The situation of indigenous peoples in Canada [cited 2020 Aug 1]. http:// unsr.jamesanaya.org/?cat=11

32. Nasser W, Beres SB, Olsen RJ, Dean MA, Rice KA, Long SW, et al. Evolutionary pathway to increased virulence and epidemic group A Streptococcus disease derived from 3,615 genome sequences. Proc Natl Acad Sci U S A. 2014;111:E176876. https://doi.org/10.1073/pnas.1403138111

33. Tyrrell GJ, Lovgren M, St Jean T, Hoang L, Patrick DM, Horsman G, et al. Epidemic of group A Streptococcus M/ emm59 causing invasive disease in Canada. Clin Infect Dis. 2010;51:1290-7. https://doi.org/10.1086/657068

34. Fittipaldi N, Beres SB, Olsen RJ, Kapur V, Shea PR, Watkins ME, et al. Full-genome dissection of an epidemic of severe invasive disease caused by a hypervirulent, recently emerged clone of group A Streptococcus. Am J Pathol. 2012;180:1522-34. https://doi.org/10.1016/j.ajpath.2011.12.037

35. Brown CC, Olsen RJ, Fittipaldi N, Morman ML, Fort PL, Neuwirth R, et al. Spread of virulent group A Streptococcus type emm59 from Montana to Wyoming, USA. Emerg Infect Dis. 2014;20:679-81. https://doi.org/10.3201/eid2004.130564

36. Engelthaler DM, Valentine M, Bowers J, Pistole J, Driebe EM, Terriquez J, et al. Hypervirulent emm 59 clone in invasive group A Streptococcus outbreak, southwestern United States. Emerg Infect Dis. 2016;22:734-8. https://doi.org/10.3201/ eid2204.151582

37. Chochua S, Metcalf BJ, Li Z, Rivers J, Mathis S, Jackson D, et al. Population and whole genome sequence based characterization of invasive group A streptococci recovered in the United States during 2015. mBio. 2017;8:e01422-17. https://doi.org/10.1128/mBio.01422-17

38. Dale JB, Penfound TA, Chiang EY, Walton WJ. New 30-valent M protein-based vaccine evokes cross-opsonic antibodies against non-vaccine serotypes of group A streptococci. Vaccine. 2011;29:8175-8. https://doi.org/ 10.1016/j.vaccine.2011.09.005

Address for correspondence: Gregory J. Tyrrell, University of Alberta Hospital, ProvLab, 2B3.08 WMC, 8440-112 St, Edmonton, AB T6G 2J2, Canada; email: gjt@ualberta.ca

\section{EID Podcast Telework during Epidemic Respiratory Illness}

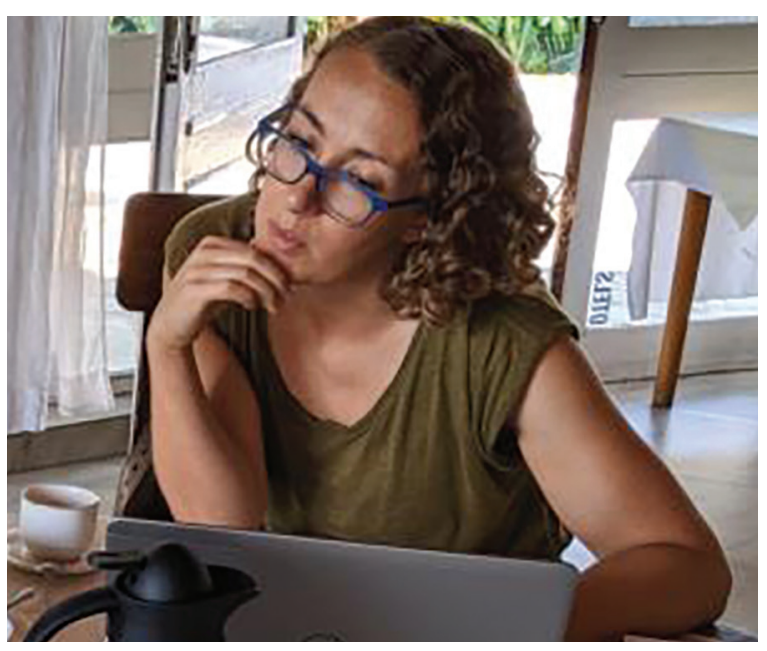

The COVID-19 pandemic has caused us to reevaluate what "work" should look like. Across the world, people have converted closets to offices, kitchen tables to desks, and curtains to videoconference backgrounds. Many employees cannot help but wonder if these changes will become a new normal.

During outbreaks of influenza, coronaviruses, and other respiratory diseases, telework is a tool to promote social distancing and prevent the spread of disease. As more people telework than ever before, employers are considering the ramifications of remote work on employees' use of sick days, paid leave, and attendance.

In this EID podcast, Dr. Faruque Ahmed, an epidemiologist at $C D C$, discusses the economic impact of telework.

\section{Visit our website to listen: https://go.usa.gov/xfcmN EMERGING INFECTIOUS DISEASES}

